\title{
HIBISCUS SABDARIFFA AQUEOUS EXTRACT AMELIORATES THIOACETAMIDE-INDUCED HEPATIC ENCEPHALOPATHY IN GUINEA PIGS: ROLE OF AMMONIA EXTRACTION
}

\section{BY}

\author{
Essam F. Alalkamy ${ }^{1}$, Amal A Mishriki ${ }^{1}$, Aida A Khattab ${ }^{1}$, Ayman M Helal ${ }^{2}$ \\ FROM \\ ${ }^{1}$ Medical Pharmacology Dpt, Faculty of Medicine, Cairo University, Egypt; ${ }^{2}$ \\ Pharmacology Dpt, Faculty of Medicine, Fayoum University, Egypt
}

\begin{abstract}
The current work assessed the preventive and therapeutic potential of Hibiscus sabdariffa "HS" aqueous extract (HSE) on thioacetamide (TAA)-induced hepatic encephalopathy (HE) associated with the acute liver injury. Method: guinea pigs were divided into: Group 1 (Control group $\boldsymbol{n = 2 4 )}$ which was further subdivided into 4 subgroups; Group "1-a" (non-treated); Group "1-b" given HSE for 3 days and sacrificed on the $4^{\text {th }}$ day; Group "1-c" given TAA for 3 days and sacrificed on the $4^{\text {th }}$ day; Group "1$d$ " given the TAA doses for 3 days and sacrificed on the $7^{\text {th }}$ day; Group 2 (Preventive) given TAA and HSE doses concurrently for 3 days and sacrificed on the $4^{\text {th }}$ day. Group 3 (Therapeutic) given 3-days TAA followed by 3-days HSE doses and sacrificed on the $7^{\text {th }}$ day. Results: Preventive and therapeutic HSE resulted in significant amelioration of the TAA-induced hepatic encephalopathy with faster recovery of animals on the $7^{\text {th }}$ day associated with significant improvement in the biochemical parameters of liver injury including the ammonia extraction ratio indicating functional hepatic improvement. In addition, there was a significant improvement in brain edema. Conclusion: HSE has both preventive and therapeutic effects on TAA-induced hepatic encephalopathy and liver injury in guinea pigs
\end{abstract}

Key words: guinea pigs, H. sabdariffa, hepatic encephalopathy, acute liver injury.

\section{Introduction}

Hepatic encephalopathy (HE) is one of the most serious complications of hepatic failure, either acute or chronic. Most patients with cirrhosis show a spectrum of reversible neuropsychiatric symptoms during the course of their disease, with up to $25 \%$ developing overt HE within 5 years after cirrhosis diagnosis and up to $80 \%$ developing minimal $\mathrm{HE}$ (Ridola et al. 2018). Overall, in addition to death risk, hepatic encephalopathy is associated with poor quality of life, impaired daily activity, decreased work productivity and frequent hospitalization for the treatment of recurrent episodes (Munoz, 2008).

The pathogenesis is multifactorial. Overall, ammonia is the best characterized neurotoxin that precipitates $\mathrm{HE}$ and it is generally accepted that ammonia plays the major role in brain dysfunction through many neurotoxic effects. Furthermore, treatment that lowers blood ammonia level can improve symptoms of hepatic encephalopathy (Munoz, 
2008). However, many other factors have been mentioned including oxidative stress, endogenous benzodiazepine-like ligands, astrocyte swelling, abnormal neurotransmission, neurosteroids and $\gamma$-aminobutyric acid-like molecules, inflammatory cytokines and others (Butterworth 2015).

Thioacetamide (TAA) is a fungicidal agent commonly used for its hepatotoxic effects in experimental studies to induce hepatic failure followed by HE (Koblihová et al. 2014). By biotransformation in the body into toxic reactive species it induces acute centrilobular liver necrosis through covalent binding with liver macromolecules (Koen et al. 2013). Hibiscus sabdariffa (HS) is a shrub (belonging to the family Malvaceae) that was used in traditional medicine. Its native origin is Asia or Tropical Africa. The flower of HS calyx contains many acids and alkaloids as polyphenolic acids, protocatechuic acid (PCA), anthocyanins and flavonoids (Mahadevan et al. 2009). HS had been involved in many studies that demonstrated its various beneficial medical effects including antihypertensive (McKay et al. 2010), antioxidant (Oboh and Rocha, 2008), hepatoprotective (Dahiru et al. 2003 and Liu et al. 2010), nootropic (Joshi and Parle, 2006), CNS depressant Khatun et al. 2011), antipyretic and anti-inflammatory actions (Dafalla and Al-Mustafa, 1996; Kao et al. 2009; Ali et al. 2011 and Ali et al 2014). Essa and Subramanian (2007), demonstrated that oral administration of alcoholic extract of $H S$ significantly normalizes the levels of ammonia, urea, uric acid, creatinine and non-protein nitrogen in the blood in ammonium chloride-induced hyperammonemic rats, that may suggest a role for the extract in management of hepatic encephalopathy. The present study was designed to investigate the possible preventive and/or therapeutic effect of Hibiscus sabdariffa flower aqueous extract on thioacetamide-induced hepatic encephalopathy and liver injury in guinea pigs.

\section{Materials and Methods:}

\section{Drug Preparation:}

- Aqueous suspension of Hibiscus sabdariffa (HS) flower powder (Hybisc 300mg/caplet; Pharma Egypt Net, Egypt, Batch No. 92973): It was provided in the form of caplets (tablets). The tablets were prepared from dried powder spray of natural aqueous extract of simply macerated flowers of Hibiscus sabdariffa L. at room temperature. The tablets were crushed and the powder was dissolved in distilled water so as to form a suspension of $250 \mathrm{mg} / 4 \mathrm{~mL}$ (Dahiru et al. 2003). It was given orally in a dose of $250 \mathrm{mg} / \mathrm{kg} / \mathrm{d}$ for three consecutive days.

- Thioacetamide (TAA) (Luba, India, Batch No. G446708): It was provided in the form of brownish powder and dissolved in saline. It was given intraperitoneally (i.p.) in a dose of $300 \mathrm{mg} / \mathrm{kg} / \mathrm{d}$ for three consecutive days.

- Reagents and kits for biochemical measurements (Biodiagnostic, Egypt).

Animal Model:

Thirty-six healthy adult Dunkin-Hartley guinea pigs weighting 450-500g were purchased from the experimental animal house of Faculty of Medicine, Cairo University. The animals were handled according to the guidelines of local ethics committee which comply with the international laws for use and care of laboratory animals. The animals 
were put in plastic cages maintained under standardized conditions (temperature $25 \pm 2{ }^{\circ} \mathrm{C}$, 12:12 h light-dark cycle and $50 \pm 5 \%$ relative humidity and were allowed a week for acclimatization before starting the study. All animals had free access to food and water and were given daily subcutaneous supportive fluids $(0.9 \%$ saline and $5 \%$ dextrose with $20 \mathrm{mEq} / \mathrm{l} \mathrm{KCl}(10 \mathrm{ml} / \mathrm{kg} / \mathrm{tid})$ (Zimmermann et al. 1989) through the study days. They were divided into the following groups: Group 1 (Control group, $\mathbf{n = 2 4}$ ) which was further subdivided into 4 subgroups; each consisted of 6 guinea pigs: Group "1-a" (non-treated control) given only the supportive fluid and were sacrificed on the $4^{\text {th }}$ day; Group " $1-b$ " (HSE control) were given HSE only and were sacrificed on the $4^{\text {th }}$ day; Group "1-c" (TAA 4-days control) were given TAA only and were sacrificed on the $4^{\text {th }}$ day; Group "1d" (TAA 7-days control) were given TAA and were sacrificed on the $7^{\text {th }}$ day; Group 2 (Preventive group) were given both TAA and HSE for 3 days and were sacrificed on the $4^{\text {th }}$ day. Group 3 (Therapeutic group) were given TAA for 3 days followed by HSE for another 3 days and were sacrificed on the $7^{\text {th }}$ day. Water vehicle and the aqueous HSE were given orally in $4 \mathrm{ml}$ volume for each $\mathrm{kg}$ per animal.

\section{Induction of Hepatic encephalopathy:}

In the current study, guinea pigs were chosen for their large size. The dose of thioacetamide was modified to be $300 \mathrm{mg} / \mathrm{kg} /$ day for three consecutive days through a pilot study to establish the best dose for induction of acute hepatic encephalopathy in guinea pigs instead of 2 days in rats (Zimmermann et al. 1989). Gupta (1956) demonstrated that TAA produces its maximal effect within 30 hours of dose injection. Therefore, conscious level assessment was done daily while biochemical and histopathological examinations were postponed for at least 24 hours after the last injected dose of TAA. In addition, thioacetamide could lead to hypoglycemia, hypotension, weight loss and renal failure (Butterworth et al. 2009), while Hibiscus sabdariffa has a blood pressure lowering effect (McKay et al. 2010). Therefore, all animals in the present study received the supportive fluids and external heating in addition to blood pressure and creatinine level monitoring (Zimmermann et al. 1989).

\section{Evaluation of Hepatic Encephalopathy:}

Conscious level was assessed before and every day during this study according to the experimental animals' grades of hepatic encephalopathy that was described by Cauli et al., (2008) (Table 1).

Table 1: Experimental animals grading system of hepatic encephalopathy (Cauli et al. 2008).

\begin{tabular}{|c|l|}
\hline Grade & \multicolumn{1}{|c|}{ Description } \\
\hline $\mathbf{0}$ & Normal \\
\hline $\mathbf{1}$ & Decreased motor activity, poor gesture control and mild ataxia \\
\hline $\mathbf{2}$ & Severe ataxia, and sedation but righting reflex is present \\
\hline $\mathbf{3}$ & No righting reflex to painful stimuli (precoma stage) \\
\hline $\mathbf{4}$ & No reaction to painful stimuli and no corneal reflex (coma stage) \\
\hline
\end{tabular}




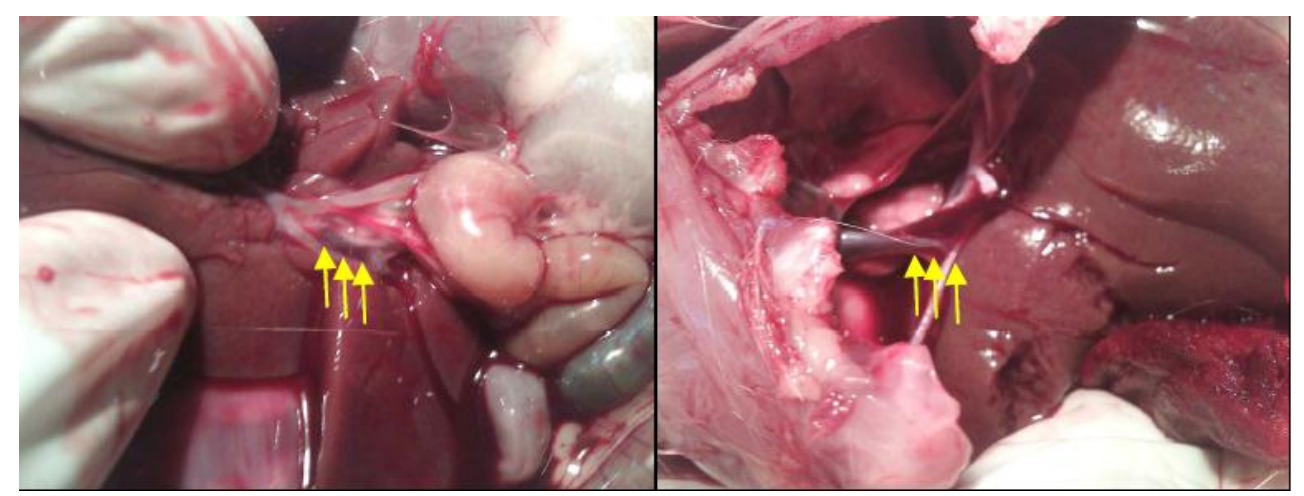

A

B

A: portal vein. B: hepatic vein

\section{Invasive Blood Pressure Measurement:}

Under anesthesia with ketamine $(100 \mathrm{mg} / \mathrm{kg})+$ diazepam $(5 \mathrm{mg} / \mathrm{kg})$ intramuscularly, the trachea was cannulated and connected to a respirator (Miniature Ideal Pump, Searle BioScience, UK). The animals were artificially ventilated with a constant volume respiration at a tidal air volume of $10 \mathrm{~mL} / \mathrm{kg}$ and a frequency of 37 strokes $/ \mathrm{min}$. The carotid artery was exposed and cannulated by a 20-gauge cannula filled with heparinized saline and connected to a BP sensitive transducer connected to the power lab device (PL4/35 ADInstruments) for recording systolic (SBP) and diastolic (DBP) and mean arterial blood pressure (ABP).

Biochemical Studies (colorimetric method):

After recording blood pressure, the hepatic and portal veins were exposed and cannulated (figures A \& B) to withdraw blood samples for measuring portal and hepatic veins ammonia (Reitman and Frankel, 1957) and to calculate the hepatic extraction ratio (HER) of ammonia using the formula:

$\mathrm{HER} \%=100 \times$ (portal vein $\mathrm{NH}_{3}$ - hepatic vein $\mathrm{NH}_{3}$ ) / portal vein $\mathrm{NH}_{3}$

This was followed by exsanguination to estimate levels of serum alanine aminotransferase (ALT) and aspartate aminotransferase (AST) (Reitman and Frankel, 1957) to confirm the presence of liver injury. Serum creatinine was measured to evaluate the kidney function (Schirmeister, 1964).

\section{Histopathological Study:}

Liver and brain specimens taken from sacrificed guinea pigs were fixed in $10 \%$ formalin immediately after removal, then processed and embedded in paraffin. The paraffin blocks were cut with rotary microtome at 4-micron thickness. The sections were stained with hematoxylin and eosin for routine histopathological examination by light microscopy. 


\section{Statistical Analysis:}

Results were presented as Mean \pm Standard deviation (SD) for all variables in the studied groups. Statistics were done using Statistical Package for Social Sciences (SPSS) 12 for data analysis. ANOVA test was used for comparing more than two groups and Tukey's test was used when ANOVA test was significant. Differences were considered significant when $\mathrm{P}$ value is $<0.05$.

\section{Results:}

Administration of HSE to normal animals in group " $1-b$ " showed comparable results to that of the animals of the non-treated control group "1-a" without significant differences denoting no apparent effect of HSE $(250 \mathrm{mg} / \mathrm{kg} / \mathrm{d})$ on the normal guinea pigs' liver and brain.

Intraperitoneal "TAA" injection in groups "1-c" and "1-d" resulted in development of $\mathrm{HE}$ as indicated by the experimental animals grading system of "HE" (table 1) (Cauli et al. 2008). All animals of the two groups had normal (Grade " 0 " HE) conscious level for the $1^{\text {st }}$ and $2^{\text {nd }}$ day. On the $3^{\text {rd }}$ day, all animals developed decreased motor activity, poor gesture control and mild ataxia (Grade " 1 " HE). On the $4^{\text {th }}$ day, all animals developed severe ataxia and sedation with presence of righting reflex (Grade " 2 " HE) (Figure 1). On the $5^{\text {th }}$ day, all animals of group "1-d" developed precoma stage with absence of righting reflex to painful stimuli (Grade " 3 " HE). All animals then reverted to grade " 2 " on $6^{\text {th }}$ day and grade " 1 " on $7^{\text {th }}$ day (Figure 1). This deterioration of conscious level in both groups was significant compared to negative control group (gp. "1-a") in which all animals had normal (Grade "0" $\mathrm{HE}$ ) conscious level throughout the study duration.

Associated with the "HE" development, the hepatic biochemical parameters (ALT, AST, portal and hepatic veins ammonia, and liver ammonia extraction ratio) measured on the $4^{\text {th }}$ and $7^{\text {th }}$ days in groups " $1-c$ " and " $1-d$ " for the animals respectively, also significantly deteriorated compared to group " $1-\mathrm{a}$ ". However, the final deteriorations were significantly less in group " $1-d$ " than that in group " $1-c$ " denoting spontaneous partial recovery of the hepatic injury on the $7^{\text {th }}$ day (Table 2). Furthermore, mean plasma levels of portal and hepatic ammonia significantly increased with reduction in ammonia extraction ratio in groups "1-c" and "1-d" compared to group "1-a".

However, serum creatinine levels showed insignificant difference in between the three groups. In addition, the mean systolic (SBP) and mean diastolic (DBP) blood pressures measured on the $4^{\text {th }}$ day in group " $1-c$ " and on the $7^{\text {th }}$ day in group " $1-d$ " showed insignificant changes compared to group "1-a" (Table 2). However, the mean arterial blood pressure was significantly lower in group "1-c" compared to group "1-a" but was not significantly lower in group " $1-d$ " which might reflect some recovery.

Histopathological examination of the livers from sacrificed animals on the $4^{\text {th }}$ day in group " $1-c$ " and on the $7^{\text {th }}$ day in group " $1-\mathrm{d}$ " revealed significant injury in all animals compared to the normal hepatic sections in group "1-a". This was evidenced by hemorrhagic necrosis, bridging necrosis, lymphocytic infiltration and blood vessels thickening in all animals (Figure 2). In addition, histopathological examination of the brain

revealed Alzheimer type II astrocytosis and brain edema in all animals both on the $4^{\text {th }}$ and 
the $7^{\text {th }}$ days. However, gliotic bands developed in 2 animals on the $4^{\text {th }}$ day and in 3 animals on the $7^{\text {th }}$ day (Figure 3 ). All these changes were significant when compared to normal findings in group " $1-\mathrm{a}$ ".

Preventive effect of Hibiscus sabdariffa aqueous extract:

\section{A) Conscious level evaluation and Biochemical Markers:}

As in group "1-c", all the 6 animals of group 2 had normal conscious level (grade 0 $\mathrm{HE}$ ) for the $1^{\text {st }}$ and $2^{\text {nd }}$ days, then they developed grade " 1 " HE on the $3^{\text {rd }}$ day (Figure 1). On the $4^{\text {th }}$ day, in contrast to group "1-c" where all the animals developed grade "2" HE, only one animal in "group 2" deteriorated to suffer from grade " 2 " HE, while the remaining 5 animals had only grade " 1 " HE. This indicated a significant prophylactic effect of HSE in preventing deterioration of conscious level from grade " 1 " to grade "2" HE in about $83 \%$ of animals within group "2" compared to group " $1-\mathrm{c}$ ".

Meanwhile, the animals of group " 2 " showed significantly better results of the hepatic biochemical parameters measured on the $4^{\text {th }}$ day compared to group "1-c" with mild elevation in AST, ALT, portal and hepatic veins ammonia, and more hepatic ammonia extraction ratio. Similarly, mean serum creatinine, SBP and DBP were not significantly changed compared to that in groups "1-a" and "1-c". However, the mean ABP was significantly lower compared to that of group "1-a", but insignificantly different from that in group "1-c" (Table 2).

Hepatic histopathological examination of the sacrificed animals in group 2 on the $4^{\text {th }}$ day revealed hepatic injury similar to that in group " $1-c$ " with no significant differences in between them (Fig. 2). In addition, histopathological examination of the brain revealed similar picture to that in group " $1-\mathrm{c}$ ", but there was brain edema in only 5 animals $(83 \%)$ compared to 6 animals in group " $1-\mathrm{c}$ " $(100 \%)$ and only one animal developed gliotic bands (17\%) compared to 2 animals in group " $1-\mathrm{c}$ " $(34 \%)$ and 3 animals on the $7^{\text {th }}$ day in group "1-d". All these changes were significant compared to normal findings in group "1-a" (Fig. $3)$. 
animal $1 \square$ animal $2 \square$ animal $3 \square$ animal $4 \square$ animal $5 \square$ animal 6

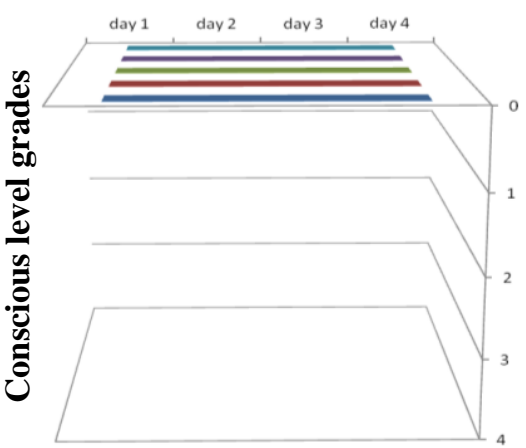

Group "1-a"

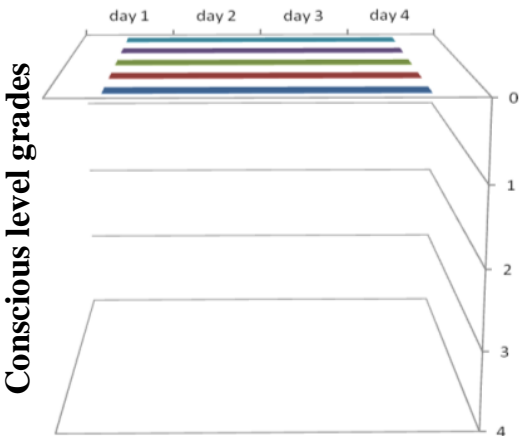

Group "1-b"

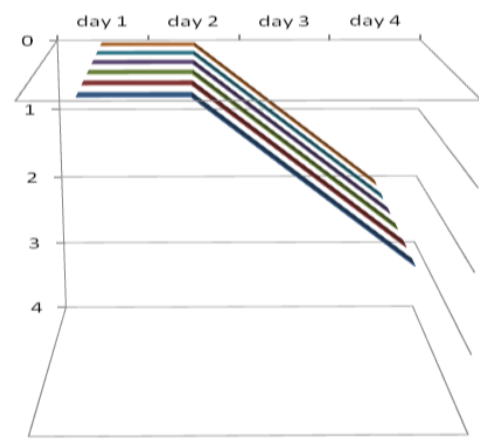

Group "1-c"

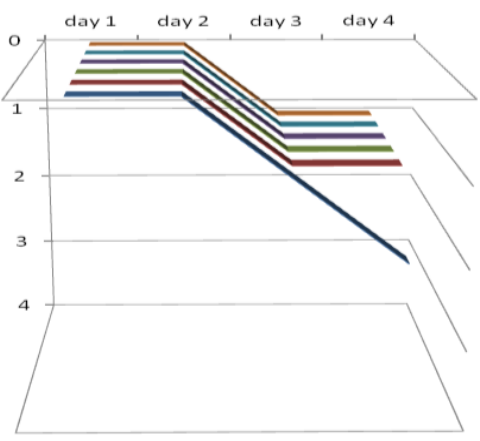

Group 2

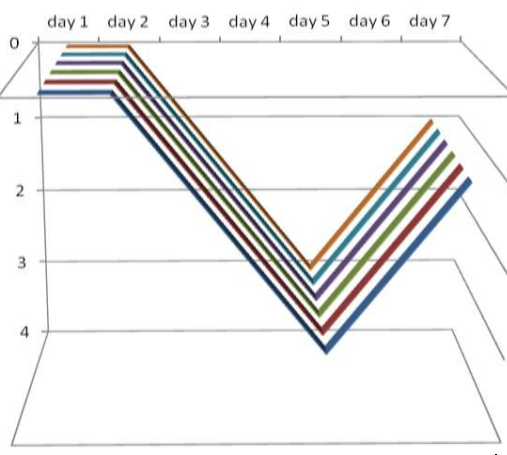

Group "1-d"

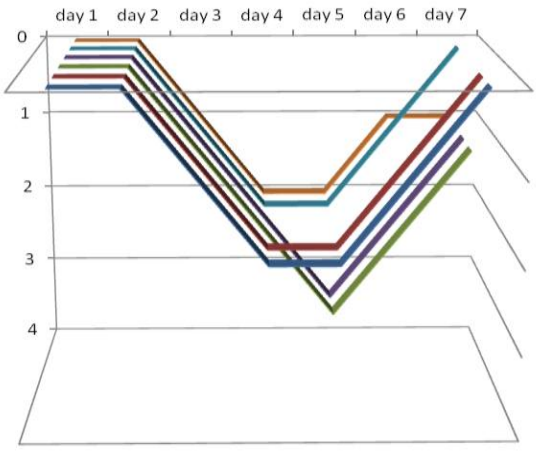

Group 3

Figure 1: Changes in conscious level throughout the study

Group "1-a" (Nontreated control) sacrificed in the $4^{\text {th }}$ day; Group "1-b" (HS-treated control) and sacrificed on the $4^{\text {th }}$ day; Group "1-c" (TAA 4-days control) given thioacetamide and sacrificed on the $4^{\text {th }}$ day; Group "1-d" (TAA 7-days control) given thioacetamide and sacrificed on the $7^{\text {th }}$ day; Group 2 (Preventive group) given both TAA $\&$ HSE for 3 days and sacrificed on the $4^{\text {th }}$ day. Group 3 (Therapeutic group) given TAA for 3 days followed by HS treatment for the next 3 days and sacrificed on the $7^{\text {th }}$ day 
Table 2: Blood pressures and biochemical changes in all animal groups throughout the study.

\begin{tabular}{|c|c|c|c|c|c|c|}
\hline & \multicolumn{4}{|c|}{ Control Groups } & \multirow{2}{*}{$\begin{array}{c}\text { Gp. "2" } \\
\text { Preventive }\end{array}$} & \multirow{2}{*}{$\begin{array}{c}\text { Gp. "3" } \\
\text { Therapeutic }\end{array}$} \\
\hline \multirow{2}{*}{ Group } & Gp. "1-a" & Gp. "1-b" & Gp. "1-c" & Gp. "1-d" & & \\
\hline & mean \pm SD & $\operatorname{mean} \pm S D$ & mean \pm SD & mean \pm SD & mean \pm SD & mean \pm SD \\
\hline $\begin{array}{l}\text { Time of } \\
\text { measurement }\end{array}$ & $4^{\text {th }}$ Day & $4^{\text {th }}$ Day & $4^{\text {th }}$ Day & $7^{\text {th }}$ Day & $4^{\text {th }}$ Day & $7^{\text {th }}$ Day \\
\hline SBP (mmHg) & $68.3 \pm 2.79$ & $67.7 \pm 2.95$ & $67.7 \pm 2.35$ & $68.2 \pm 1.79$ & $67.2 \pm 2.53$ & $68.3 \pm 2.08$ \\
\hline DBP (mmHg) & $41.1 \pm 1.59$ & $40.1 \pm 0.94$ & $39.1 \pm 1.69$ & $40.8 \pm 1.62$ & $38.9 \pm 1.04$ & $39.4 \pm 0.99$ \\
\hline $\begin{array}{l}\text { Mean BP } \\
(\mathrm{mmHg})\end{array}$ & $50.2 \pm 1.33$ & $49.3 \pm 1.35$ & $48.7 \pm 0.67 *$ & $50.1 \pm 1.15$ & $48.3 \pm 0.75^{*}$ & $49 \pm 0.88$ \\
\hline $\begin{array}{l}\text { Portal } \mathrm{NH}_{3} \\
\text { (umol/l) }\end{array}$ & $279.7 \pm 13.2$ & $276.4 \pm 11.02$ & $339.8 \pm 17.28 *$ & $307.2 \pm 14.02 *$ & $328.7 \pm 19.52 *$ & $294.6 \pm 17.86^{*}$ \\
\hline $\begin{array}{l}\text { Hepatic } \mathrm{NH}_{3} \\
\text { (umol/l) }\end{array}$ & $78.1+\underline{8} .13$ & $74.3 \pm 12.31$ & $165.5 \pm 13.88^{*}$ & $139.7 \pm 12.64 *$ & $136.3 \pm 16.25 *$ & $103.5 \pm 12.41 *$ *¥ \\
\hline HER\% & $72.1 \pm 5.61$ & $73.1 \pm 8.71$ & $51.3 \pm 7.01 *$ & $54.5 \pm 6.01 *$ & $58.5 \pm 6.71^{*}$ & $64.1 \pm 9.71^{* ¥ \pm}$ \\
\hline AST (U/L) & $47.3 \pm 7.69$ & $41.2 \pm 5.19$ & $416.8 \pm 55.49 *$ & $172.8 \pm 40.57^{*}$ & $211 \pm 54.12^{* *}$ & $104.8 \pm 15.19^{* \neq \pm}$ \\
\hline ALT (U/L) & $40.5 \pm 8.96$ & $35.3 \pm 4.89$ & $390.5 \pm 52.23 *$ & $156.8 \pm 39.34 *^{*}$ & $197.3 \pm 42.01{ }^{* *}$ & $86.5 \pm 15.45^{* ¥ f}$ \\
\hline $\begin{array}{l}\text { Creatinine } \\
(\mathrm{mg} / \mathrm{dl})\end{array}$ & $0.75 \pm 0.11$ & $0.78 \pm 0.09$ & $0.75 \pm 0.14$ & $0.77 \pm 0.11$ & $0.77 \pm 0.11$ & $0.72 \pm 0.12$ \\
\hline
\end{tabular}

Group "1-a" (Nontreated control) sacrificed in the $4^{\text {th }}$ day; Group "1-b" (HS-treated control) and sacrificed on the $4^{\text {th }}$ day; Group "1-c" (TAA 4-days control) given thioacetamide and sacrificed on the $4^{\text {th }}$ day; Group "1-d" (TAA 7-days control) given thioacetamide and sacrificed on the $7^{\text {th }}$ day; Group 2 (Preventive group) given both TAA \& HSE for 3 days and sacrificed on the $4^{\text {th }}$ day. Group 3 (Therapeutic group) given TAA for 3 days followed by HSE treatment for the next 3 days and sacrificed on the $7^{\text {th }}$ day. SBP: systolic blood pressure, DBP: diastolic blood pressure, Mean BP: mean blood pressure, HER: hepatic extraction ratio of ammonia, ALT: alanine aminotransferase, AST: aspartate aminotransferase

*: Significant compared to group " $1-\mathrm{a}$ "

¥: Significant compared to group " $1-c$ "

£:Significant compared to group "1-d"

\section{Therapeutic effect of Hibiscus sabdariffa aqueous extract}

The conscious level of the animals in group 3 followed that in group "1-d" till the $4^{\text {th }}$ day - as mentioned above - but from the $5^{\text {th }}$ day there was significant improvement evidenced by less deterioration in the conscious level and faster and complete recovery of 3 animals (50\%) to normal conscious level (grade $0 \mathrm{HE}$ ) (Figure1). On the $5^{\text {th }}$ day, in contrast to group "1-d" where all the animals developed precoma stage (grade $3 \mathrm{HE}$ ), H. sabdariffa prevented deterioration of consciousness in 4 animals to grade 3 so that only 2 animals 
developed "grade $3 \mathrm{HE}$ ". In addition, starting from the $6^{\text {th }}$ day, there was faster recovery in group 3 than in group " $1-d$ " evidenced by reversion of the animals to a one grade less in the hepatic encephalopathy scale which means improvement in conscious level i.e. 4 animals suffered from grade $1 \mathrm{HE}$ while only 2 animals had grade $2 \mathrm{HE}$ compared to development of grade 2 HE in all animals of group " $1-d$ ". Furthermore, on the $7^{\text {th }}$ day, 3 animals reverted to normal (Grade $0 \mathrm{HE}$ ) while the remaining 3 animals had grade $1 \mathrm{HE}$ in contrast to reversion to grade one in all the animals of group "1-d". This indicated a significant therapeutic effect of Hibiscus sabdariffa in treating deterioration of conscious level starting from the $5^{\text {th }}$ day $\left(2^{\text {nd }}\right.$ day of starting $H$. sabdariffa).

Along with better HE scores, the biochemical parameters (ALT, AST, portal and hepatic veins ammonia, and hepatic ammonia extraction ratio) significantly improved compared to group " $1-d$ ". However, mean serum creatinine, mean SBP, DBP and ABP were not significantly changed compared to that in groups "1-a" and "1-d". (Table 2).

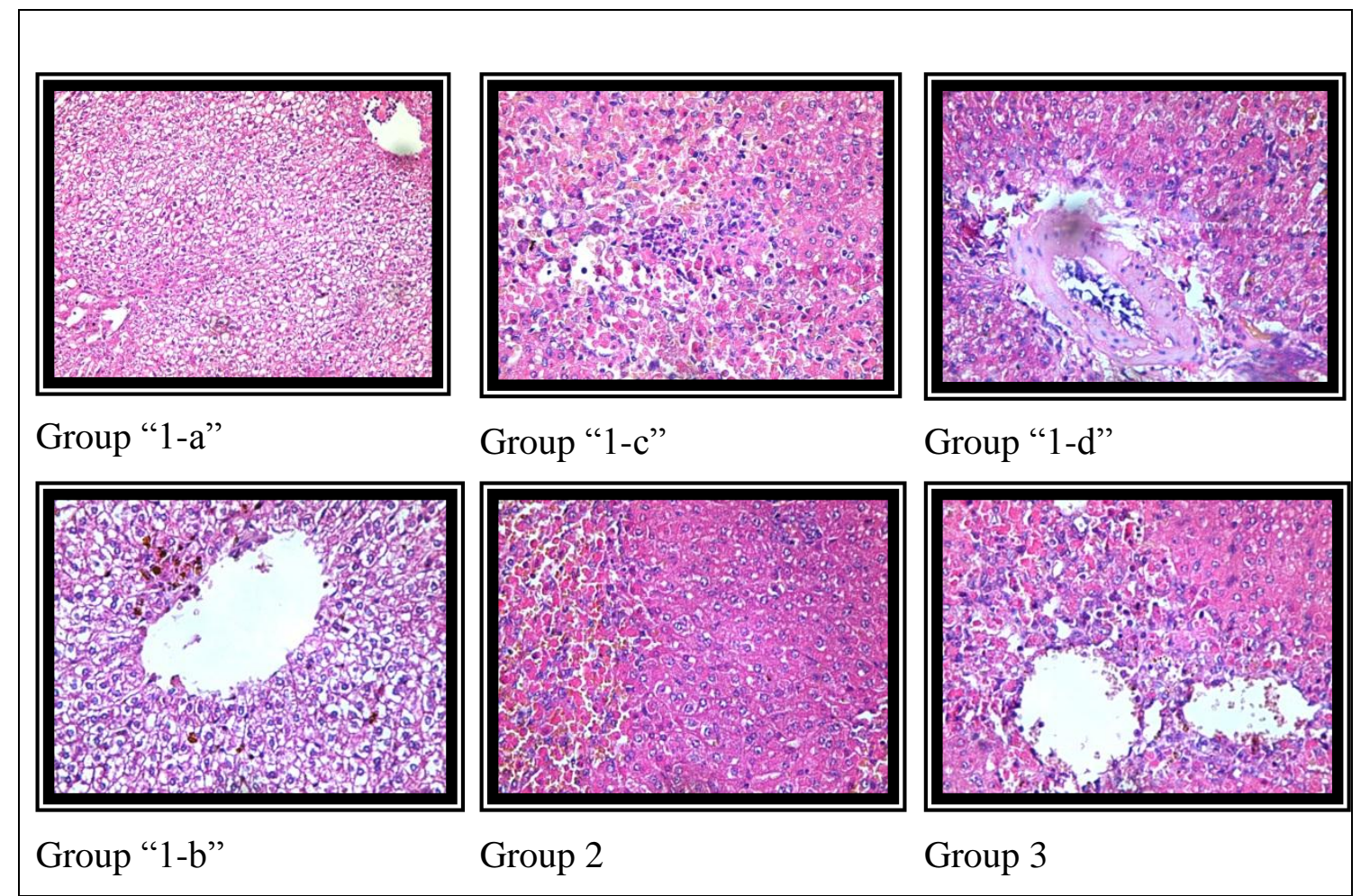

Figure 2: Sections of livers taken from guinea pigs on the $4^{\text {th }}$ day in groups "1-a", "1b", " $1-c$ " and " 2 " and on the $7^{\text {th }}$ day in groups " $1-d$ " and " 3 " 


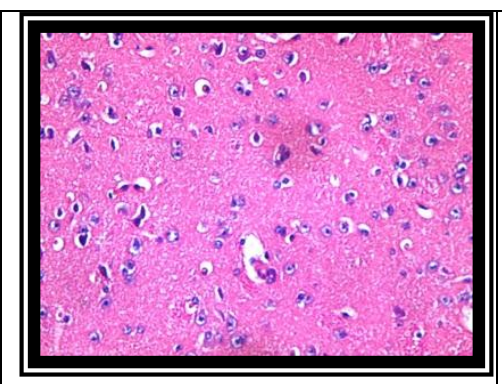

Group " $1-b$ "

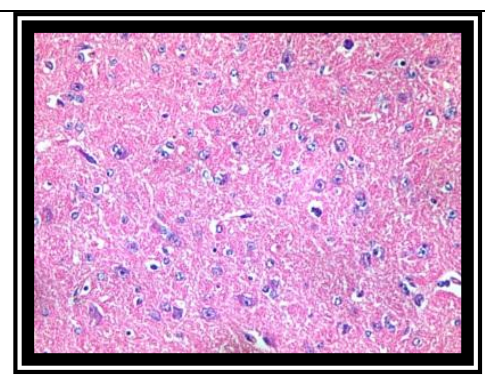

Group 2

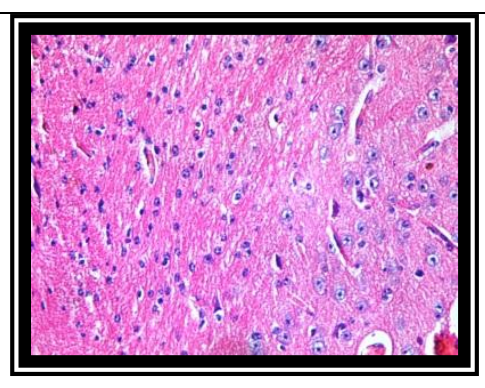

Group 3

Figure 3: Sections of brains taken from guinea pigs on the $4^{\text {th }}$ day in groups "1-a", "1b", "1-c" and " 2 " and on the $7^{\text {th }}$ day in group " $1-d$ " and " 3 ".

Group "1-a" (Nontreated control) sacrificed in the $4^{\text {th }}$ day; Group "1-b" (HS-treated control) and sacrificed on the $4^{\text {th }}$ day; Group "1-c" (TAA 4-days control) given thioacetamide and sacrificed on the $4^{\text {th }}$ day; Group "1-d" (TAA 7-days control) given thioacetamide and sacrificed on the $7^{\text {th }}$ day; Group 2 (Preventive group) given both TAA $\&$ HSE for 3 days and sacrificed on the $4^{\text {th }}$ day. Group 3 (Therapeutic group) given TAA for 3 days followed by HSE treatment for the next 3 days

Liver histopathology showed similar injury as that of group "1-d" with insignificant differences. In addition, brain histopathology showed Alzheimer type II astrocytosis in all animals and gliotic bands in 50\% of animals in both groups. However, there was a significant improvement of brain edema in about $50 \%$ of animals in group 3 compared to group "1-d" (Fig. $2 \& 3$ ).

\section{Discussion}

The results of the current study demonstrate that HSE treatment has both protective and therapeutic effects evidenced by attenuating the manifestations of hepatic encephalopathy induced by i.p. thioacetamide injection in guinea pigs and hastening their recovery. This amelioration is accompanied by better liver function tests and some improvement in the hepatic and brain histology. Furthermore, its effect is most probably due to increased hepatic ammonia extraction.

HE has been largely studied in different animals as murine models (Rahman and Hodgson, 2000). To the best of our knowledge, no studies have used guinea pig as an experimental model of HE. However, we used guinea pigs because of its larger size and ease of their handling after pilot experiments to confirm development of TAA-induced hepatic injury and HE. In the present study, induction of hepatic encephalopathy in control groups; group "1-c" (TAA 4-days control) and group "1-d" (TAA 7-days control), resulted in significant progressive development of liver injury (evidenced biochemically) and hepatic encephalopathy (evidenced by the experimental animals grading system of HE) up to the $5^{\text {th }}$ day followed by gradual improvement starting from the $6^{\text {th }}$ day denoting spontaneous partial recovery. Furthermore, histopathological examination of the livers and brains from sacrificed animals showed significant hepatic injury, brain edema and Alzheimer type II astrocytosis in all animals with no significant difference between those sacrificed on $4^{\text {th }}$ and those sacrificed on $7^{\text {th }}$ day except for development of gliotic bands in 2 
animals on the $4^{\text {th }}$ day and in 3 animals on the $7^{\text {th }}$ day. All these changes were significant compared to the normal findings in group " $1-\mathrm{a}$ ".

The TAA-induced hepatic injury and HE have been established in many studies biochemically and histologically with increased blood ammonia levels (Zimmermann et al. 1989; Abdel-hameed et al. 2014; Stefanello et al. 2015 and Lebda et al. 2018). They reported oxidative damage in liver and brain tissues indicated by increased intracellular reactive oxygen species (ROS) production (Bruck et al. 2004; Fazal et al. 2015 and Stefanello et al. 2015). These "ROS" interfere with energy utilization by exerting toxic effects on the liver mitochondria (Chu et al. 2001) and bind covalently to liver macromolecules leading to leakage of destructive hydrolytic proteases as calpains from dying cells (Chilakapati et al. 2005). In addition, the "ROS" play a basic role in the pathogenesis of TAA-induced HE, where inhibition in the antioxidant defenses is accompanied by a higher rate of lipid peroxidation and induction of cellular dysfunction and cell-membrane-protein degradation. Thus, the activities of several important membrane-bound enzymes are disturbed with $\mathrm{Na}^{+} / \mathrm{K}^{+}$-ATPase inhibition which may lead to the fulminant $\mathrm{HE}$ (Zarros et al 2008). Along with the oxidative stress, secondary inflammatory mechanisms lead to further progression of injury as TAA-associated NF- $\kappa \mathrm{B}$ activation and increased iNOS production are involved in the pathogenesis of acute hepatocellular injury and dysfunction (Chen et al. 2008). Moreover, TAA increases plasma levels of TNF- $\alpha$ and endotoxin that correlate with the severity of HE (Apte et al. 2003). In summary, endotoxin and TNF- $\alpha$ in association with glutamine accumulation induced by elevated serum ammonia produce a state of central neuroinflammatory response and astrocyte swelling leading to alterations of the morphology of neuroglial cells and microglial activation. These factors may cause dysfunction of the cerebral endothelium that leads to alteration in the permeability of the blood brain barrier with formation of brain edema. In addition, TNF- $\alpha$ induces cerebral endothelial nitric oxide synthase to synthesize nitric oxide that further affect the cerebral circulation and neuronal function (Chu et al. 2001). Ammonia, in addition, has multiple actions on CNS function that include direct effects of the ammonium ion $\left(\mathrm{NH}^{+}\right)$on both excitatory and inhibitory neurotransmission, inhibition of glucose (pyruvate) oxidation and stimulation of glycolysis, altered mitochondrial function and impairment of key cellular transport systems. Moreover, there are alterations in expression of genes coding for neuroglial proteins involved in cell volume regulation and brain metabolism as well as in the transport of amino acids and in the synthesis of pro-inflammatory cytokines (Butterworth, 2015).

Oral administration of the TAA with the HSE doses (preventive) to the animals of group "2" and after TAA doses (therapeutic) to the animals of group " 3 " significantly ameliorated the HE scores of "HE" with faster and complete recovery of $50 \%$ of animals on the $7^{\text {th }}$ day. In addition, there were similar significant improvements in the biochemical parameters of liver injury; ALT, AST, hepatic vein ammonia, and ammonia extraction ratio indicating functional hepatic improvement. However, there were no significant hepatic histopathological differences between the treated groups (group 2 and 3) and the corresponding control groups (group 1-c and "1-d" respectively). Meanwhile, brain histopathology showed small but significant improvement in one animal in group " 2 " and 
in 3 animals (50\%) in group 3 in the form of elimination of edema and gliotic bands compared to groups "1-c" and "1-d", respectively.

Previous studies on different dried HSE reported direct antioxidant and hepatoprotective activity in different experimental models. In rat primary hepatocytes cultures, HSE significantly inhibited the unscheduled DNA synthesis (UDS), the leakage of lactate dehydrogenase (LDH) and the formation of malondialdehyde (MDA) (Tseng et al. 1997) and reduced liver inflammation and necrosis (Wang et al. 2000). Other studies also reported the antioxidative hepatoprotective activity of $\mathrm{HSE}$ against $\mathrm{CCl}_{4}$-induced fibrosis (Liu et al. 2006), gamma radiation-induced (Adaramoye et al. 2008), and paracetamolinduced liver damage in rats (Ali et al. 2003) and in mice (Orji BO and Obi, 2017). These studies documented lowered serum levels of hepatic enzyme markers (ALT, AST \& GGT) and restored significantly SOD, CAT, GSH and GSH-Px and inhibited the formation of lipid peroxidative products leading to reduced oxidative liver damage. Along with these effects, a nootropic has been reported against the scopolamine-induced amnesic deficit in mice (Joshi and Parle, 2006). They attributed the CNS activity enhancement of the extract to its antioxidant, neuroprotective, procholinergic and anti-cholinesterase properties. Oboh and Rocha (2008), attributed the neuroprotective activity to its inhibitory effect on lipid peroxidation and pro-oxidant-induced lipid peroxidation in the rat's brain homogenates in a dose-dependent manner and had the ability to chelate Fe (II) and scavenge $\mathrm{OH}$ radical. However, Khatun et al. (2011), reported CNS depressant activity of HSE with reduction in spontaneous motor activity and exploratory behavior and prolongation of pentobarbital induced sleep in rats (Amos et al. 2003). Moreover, the anti-inflammatory activity of the HSE has been reported in liposome peroxidation and COX enzyme inhibition assays (Christian et al. 2006), in mice model of xylene-induced ear edema that indicated inhibitory effect of the extract on prostaglandins (mainly $\mathrm{PGI}_{2}$ and $\mathrm{PGE}$ ) in a dose-related manner (Ali et al. 2011) and in acute (carrageenan induced paw edema and acetic acidinduced vascular permeability) and chronic (cotton pellet-induced granuloma) models of inflammation. This effect indicated the ability of the extract to inhibit different inflammatory mediators as prostaglandins, histamine, leukotrienes and proliferation of microphages, neutrophils, fibroblasts and collagen formation (Ali et al. 2014).

To reveal the molecular mechanism of HSE as hepatoprotective and antiinflammatory, Kao et al. (2009), reported that the extract, beside the improvement in liver and oxidative markers, reduced the $\mathrm{NO}$ and $\mathrm{PGE}_{2}$ production, and reduced COX-2/iNOS protein expression in lipopolysaccharide (LPS)-treated macrophages. Moreover, Liu et al. (2010) documented decreased expression of pJNK, Bax and tBid in the liver that indicates cell apoptosis reduction via mitochondrial intrinsic pathways beside its anti-oxidative activity. Furthermore, HS-pretreatment inhibited the LPS-induced activation of hepatic JNK which plays a crucial role in many signaling pathways of cell death and p38 MAPK (key regulator of pro-inflammatory cytokines biosynthesis). The authors suggested that by inhibiting this activation, it can suppress NFKB translocation and subsequently decrease the protein levels of COX-2. The suggestion that HSE can affect NFKB was recently reported by Chiu, (2015), who found that HSE can down-regulate Akt/NFkB/MMP-9 Pathway 
while Shen, (2017), extracted new polysaccharides from HS that have immune-enhancing activity via MAPK and NFאB signaling pathways in RAW264.7 cells.

In contrast to the present results, Dafallah and Al Mustafa, (1996), found that HS was devoid of any anti-inflammatory activity as shown in a rat model of carrageenaninduced paw edema, however, the extract had an analgesic and antipyretic effect. Yin et al. (2010), reported that pre-treatment but not post-treatment of the cultured hepatocytes of Cyprinus carpio fish with different doses of $\mathrm{HSE}$ has protective effect against $\mathrm{CCl}_{4}$-induced damage regarding LDH, AST, ALT, SOD and GSH-Px. This lack of effect may be due to different extraction method of HS or may be due to different model.

In contrast to the present results, Yin et al. (2010), stated that post-treatment of the hepatocytes but not pre-treatment with different doses of HSE did not show any protective effect regarding LDH, AST, ALT, SOD and GSH-Px against $\mathrm{CCl}_{4}$-induced hepatocyte damage in Cyprinus carpio fish. Dafallah and Al Mustafa, (1996), found that HS is devoid of any anti-inflammatory as shown by the Carrageenan induced edema. however, the extract has an analgesic and antipyretic effect. This lack of effect may be due to different extraction method of HS or may be due to different model.

On the other hand, the results of the current study revealed an increase in the hepatic ammonia extraction ratio despite unchanged portal ammonia level that can be an additional factor in the improvement of both hepatic encephalopathy and hepatic damage. Previous studies linked elevated blood ammonia with hepatic encephalopathy and oxidative stress through increased production of NO by induction of iNOS (Schliess et al. 2002). In support of this finding is the study of Essa and Subramanian, (2007), who found that induction of hyperammonemia per se by daily IP injection of ammonium chloride in Wistar rats, resulted in increase in the levels of urea, AST, ALT, ALP, TBARS and hydroperoxides (HP). These changes were significantly decreased by treatment with HSE. They attributed this effect to the antioxidative activity of HS beside its lowering effect of the toxic hyperammonemia.

There was insignificant decrease in average systolic, diastolic and mean blood pressure compared to group "1-a" in contrast to previous studies (McKay et al. 2010 and Wahabi et al 2010). These controversies may be due to different models and different method of HSE extraction. Also, all these studies investigated, were used hypertensive models where the present study used a normotensive model and all animals were given supportive fluids.

Conclusions: Hibiscus sabdariffa has both preventive and therapeutic effects in thioacetamide-induced hepatic encephalopathy in guinea pigs. Beside its antioxidative and anti-inflammatory activity in hepatoprotection, the HSE can improve the hepatic encephalopathy by increasing the hepatic ammonia extraction through ameliorating the dysfunctional activity of the liver. These activities may suggest a clinical role in the prophylaxis and management of hepatic encephalopathy associated with liver injury and cirrhosis 


\section{REFERENCES}

Abdel-hameed OM, Abdel-Salam NM and Syam NRR. (2014) Biochemical effects of propolis and bee pollen in experimentally-induced hyperammonemia in rats. Benha Veterinary Medical Journal ; 27(1): 8-24.

Adaramoye O, Ogungbenro B, Anyaegbu O and Fafunso M.(2008) Protective effects of extracts of Vernonia amygdalina, Hibiscus sabdariffa and vitamin $\mathrm{C}$ against radiationinduced liver damage in rats. J Radiat Res,; 49(2): 123-131.

Ali BH, Mousa HM and El-Mougy S.(2003) The Effect of a water extract and anthocyanins of Hibiscus sabdariffa L. on paracetamol-induced hepatoxicity in Rats. Phytother Res,; 17: 56-59.

Ali MDK, Ashraf A, Biswas NN, Karmakar UK and Afroz S.(2011) Antinociceptive, anti-inflammatory and antidiarrheal activities of ethanolic calyx extract of HS in mice. Journal of Chinese Integrative Medicine,; 9(6): 626-631.

Ali SAE, Mohamed AH and Elazhari GE. Fatty acid composition , anti-inflammatory and analgesic activities of Hibiscus sabdariffa Linn . seeds. J Adv Vet Anim Res, 2014; 1(2): 50-57.

Amos S, Binda L, Chindo BA, Tseja A, Odutola AA, Wambebe C and Gamaniel K. (2003) Neuropharmacological effects of Hibiscus sabdariffa aqueous extract. Pharmaceutical Biology,; 41(5): 325-329.

Apte UM, Limaye PB, Desaiah D, Bucci T, Warbritton A and Mehendale HM. (2003) Mechanisms of increased liver tissue repair and survival in diet-restricted rats treated with equitoxic doses of thioacetamide. Toxicological Sciences,; 72(3): 272-282.

Bruck R, Aeed H, Avni Y, Shirin H, Matas Z, Shahmurov M, Avinoach I, Zozulya G, Weizman N and Hochman A. (2004) Melatonin inhibits nuclear factor kappa B activation and oxidative stress and protects against thioacetamide induced liver damage in rats. Journal of Hepatology,; 40: 86-93

Butterworth RF. (2015) Pathogenesis of hepatic encephalopathy and brain edema in acute liver failure. J Clin Exp Hepatol,; 5(S1): S96-S103.

Butterworth RF, Norenberg MD, Felipo V, Ferenci P, Albrecht J and Blei AT. (2009) Experimental models of hepatic encephalopathy: ISHEN guidelines. Liver Int,; 29(6): 783-788.

Cauli O, Rodrigo R, Boix J, Piedrafita B, Agusti A and Felipo V. (2008) Acute liver failure-induced death of rats is delayed or prevented by blocking NMDA receptors in brain Acute liver failure-induced death of rats is delayed or prevented by blocking NMDA receptors in brain. Am J Physiol Gastrointest Liver Physiol,; 295: G503G511.

Chen TM, Subeq YM, Lee RP, Chiou TW and Hsu BG. (2008) Single dose intravenous thioacetamide administration as a model of acute liver damage in rats. Int $\mathbf{J}$ Exp Pathol,; 89: 223-231. 
Chilakapati J, Shankar K, Korrapati MC, Hill RA and Mehendale HM. (2005) Saturation toxicokinetics of thioacetamide: role in initiation of liver injury. Drug Metab Dispos,; 33(12):1877-1885.

Chiu CT, Chen JH, Chou FP and Lin HH. (2015) Hibiscus sabdariffa leaf extract inhibits human prostate cancer cell invasion via down-regulation of $\mathrm{Akt} /$ NFkB/MMP-9 pathway. Nutrients,; 7: 5065-5087.

Christian, KR, Nair, MG and Jackson JC. (2006) Antioxidant and cyclooxygenase inhibitory activity of sorrel (Hibiscus sabdariffa). Journal of Food Composition and Analysis,; 19: 778-783.

Chu CJ, Chen CT, Wang SS, Lee FY, Chang FY, Lin HC, Wu SL, Lu RH, Chan CC, Huang HC and Lee SD. (2001) Hepatic encephalopathy in rats with thioacetamideinduced fulminant hepatic failure: role of endotoxin and tumor necrosis factor-alpha. Chinese Medical Journal (Taipei),; 64: 321-330.

Dafalla AA and Al-Mustafa Z. (1996) Investigation of the anti-inflammatory activity of Acacia nilotica and Hibiscus sabdariffa. American Journal of Chinese Medicine,; 24: 263-269.

Dahiru D, Obi OJ and Umaru H. Effect of Hibiscus sabdariffa calyx extract on carbon tetrachloride induced liver damage. Biokemistri, 2003; 15(1): 27-33.

Essa MM and Subramanian P. Hibiscus sabdariffa affects ammonium chloride-induced hyperammonemic rats. Evidence-Based Complementary and Alternative Medicine,; 4(3), 321-325.

Fazal Y, Fatima SN, Shahid SM and Mahboob T. (2007) Effects of curcumin on angiotensin converting enzyme gene expression, oxidative stress and anti-oxidant status in thioacetamide-induced hepatotoxicity. J Renin Angiotensin Aldosterone Syst, 2015; 16(4): 1046-1051.

Gupta D. (1956) Acute changes in the liver after administration of thioacetamide. The Journal of Pathology and Bacteriology,; 72: 183-192.

Joshi H and Parle M. (2006) Nootropic activity of calyces of Hibiscus sabdariffa. Iranian Journal of Pharmacology and Therapeutics,; 5(1), 15-20.

Kao ES, Hsu JD, Wang CJ, Yang SH, Cheng SY and Lee HJ. (2009) Polyphenols extracted from Hibiscus sabdariffa L. inhibited lipopolysaccharide-induced inflammation by improving antioxidative conditions and regulating cyclooxygenase 2 expression. Bioscience, Biotechnology and Biochemistry,; 73(2): 385-390.

Khatun MH, Rafikul Islam M, Mamun A, Nahar L, Luthfunnesa, Anwar Ul and Islam (2011) M. In Vivo evaluation of CNS depressant and antinociceptive activities of methanol extract of Hibiscus sabdariffa fruits. Journal of Applied Sciences,; 7(6): 798-804. 
Koblihová E, Mrazova I, Vernerova $Z$ and Ryska M. (2014) Acute liver failure induced by thioacetamide: selection of optimal dosage in Wistar and Lewis rats. Physiol. Res.,; 63: 491-503.

Koen YM, Sarma D, Hajovsky H, Galeva NA, Williams TD, Staudinger JL and Hanzlik RP. (2013) Protein targets of thioacetamide metabolites in rat hHepatocytes. Chem. Res. Toxicol,; 26, 564-574.

Lebda MA, Sadek KM, Abouzed TK, Tohamy HG and El-Sayed YS. (2018) Melatonin mitigates thioacetamide-induced hepatic fibrosis via antioxidant activity and modulation of proinflammatory cytokines and fibrogenic genes. Life Sciences,; 192: 136-143.

Liu JY, Chen CC, Wang WH, Hsu JD, Yang MY and Wang CJ. (2006) The protective effects of Hibiscus sabdariffa extract on $\mathrm{CCl}_{4}$-induced liver fibrosis in rats. Food and Chemical Toxicology,; 44: 336-343.

Liu LC, Wang CJ, Lee CC, Su SC, Chen HL, Hsu JD and Lee HJ. (2010) Aqueous extract of Hibiscus sabdariffa L. decelerates acetaminophen-induced acute liver damage by reducing cell death and oxidative stress in mouse experimental models. J Sci Food Agric,; 90: 329-337.

Mahadevan N, Shivali and Kamboj P. (2009) Hibiscus sabdariffa - An overview. Natural Product Radiance,; 8(1): 77-83.

McKay DL, Chen CO, Saltzman E and Blumberg JB. (2010) Hibiscus sabdariffa tea lowers blood pressure in prehypertensive and mildly hypertensive adults. The Journal of Nutrition,; 140(3): 298-303.

Munoz SJ. (2008) Hepatic encephalopathy. Emergency Medicine Clinics of North America; 92(4): 795-812.

Oboh G and Rocha JBT. (2008) Antioxidant and neuroprotective properties of sour tea (Hibiscus sabdariffa, calyx) and green tea (Camellia sinensis) on some pro-oxidantinduced lipid peroxidation in brain in vitro. Food Biophysics,; 3(4): 382-389.

Orji BO and Obi FO. (2017) Effects of concurrent administration of paracetamol and aqueous extract of Hibiscus sabdariffa Linn calyx on paracetamol hepatotoxicity in mice. J Pharm Chem Biol Sci,; 5(2): 108-117.

Rahman TM and Hodgson HJF. (2000) Animal models of acute hepatic failure. Int J Exp Path,; 81: 145-157.

Reitman S and Frankel S A. (1957) Colorimetric method for the determination of serum glutamic oxalacetic and glutamic pyruvic transaminases. Amer J Clin Patho,; 28(1):56-63.

Ridola L, Cardinale V and Riggio O. (2018) The burden of minimal hepatic encephalopathy: from diagnosis to therapeutic strategies. Ann. Gastroenterol.,; 31: $151-164$ 
Schirmeister, J. (1964) Determination of creatinine in serum. Dtsch. med Wschr.;,89:1940.

Schliess F, Gorg B, Fischer R, Desjardins P, Bidmon HJ, Herrmann A, Butterworth RF, Zilles $\mathbf{K}$ and Häussinger D. (2002) Ammonia induces MK-801-sensitive nitration and phosphorylation of protein tyrosine and residues in rat astrocytes. FASEB J,; 16:739-741.

Shen CY, Zhang WL and Jiang JG. (2017) Immune-enhancing activity of polysaccharides from Hibiscus sabdariffa Linn. via MAPK and NF-kB signaling pathways in RAW264.7 cells. Journal of Functional Foods,; 34: 118-129.

Stefanello ST, da Rosa EJF, Dobrachinski F, Amaral GP, de Carvalho NR, da Luz SCA, Bender CR, Schwab RS, Dornelles L and Soares FAA. (2015) Effect of diselenide administration in thioacetamide-induced acute neurological and hepatic failure in mice. Toxicol Res; 4(3): 707-717.

Tseng TH, Kao ES, Chu CY, Chou FP, Wu HWL and Wang CJ. (1997) Protective Effects of Dried Flower Extracts of Hibiscus sabdariffa L. against oxidative stress in rat primary hepatocytes. Food and Chemical Toxicology,; 35: 1159-1164.

Wahabi HA, Alansary LA, Al-Sabban AH and Glasziuo P. The effectiveness of Hibiscus sabdariffa in the treatment of hypertension: A systematic review. Phytomedicine, 2010; 17(5): 83-86.

Wang CJ, Wang JM, Lin WL, Chu CY, Chou FP and Tseng TH. (2000) Protective effect of Hibiscus anthocyanins against tert-butyl hydroperoxide-induced hepatic toxicity in rats. Food and Chemical Toxicology,; 38: 411-416.

Yin G, Cao L, Xu P, Jeney G and Nakao M. (2010) Hepatoprotective and antioxidant effects of Hibiscus sabdariffa extract against carbon tetrachloride-induced hepatocyte damage in Cyprinus carpio. In Vitro Cellular and Developmental Biology - Animal, 2010; 47: 10-15.

Zarros A, Theocharis S, Skandali $\mathbf{N}$ and Tsakiris S.(2008) Effects of fulminant hepatic encephalopathy on the adult rat brain antioxidant status and the activities of acetylcholinesterase, $(\mathrm{Na}+\mathrm{K}+)$ - and $\mathrm{Mg} 2+-\mathrm{ATPase}$ : comparison of the enzymes' response to in vitro treatment with ammonia. Metab Brain Dis, 2008; 23: 255-264.

Zimmermann C, Ferenci P, Pifl C, Yurdaydin C, Ebner J, Lassmann H, Roth E and Hortnagl H.(1989) Hepatic encephalopathy in thioacetamide-induced acute liver failure in rats: characterization of an improved model and study of amino acid-ergic neurotransmission. Hepatology, 1989; 9(4): 594-601. 


\section{تحسين الإعتلال الاماغي الكبدي المستحث بالثيوأسيتامايد بالخلاصة المائية للكركديه (هايبسكس

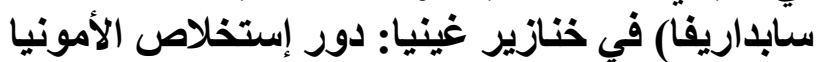 \\ لإدادة الدكاتزة \\ 'عصام فؤاد العلقامي ، 'امال مشرقي ، 'عايدة خطاب ، 'اليمن هلال

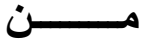 \\ 'قسم فارماكولوجي الطبية كلية طب جامعة القاهرة

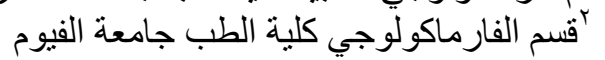

ليؤدي التلف الكبدي الحاد إلى ارتفاع الأمونبا في الدم الثرياني و الذي يرتبط بشكل إيجابي باختلال وظائف الجهاز

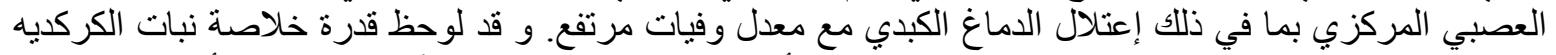
(Hibiscus (sabdariffa L. HS

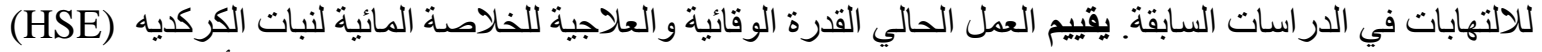

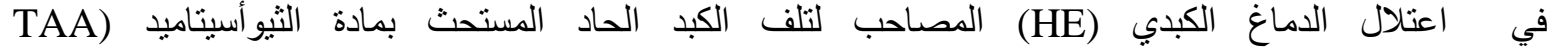
.(Thioacetamide

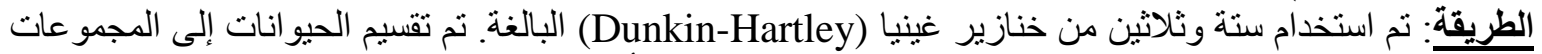

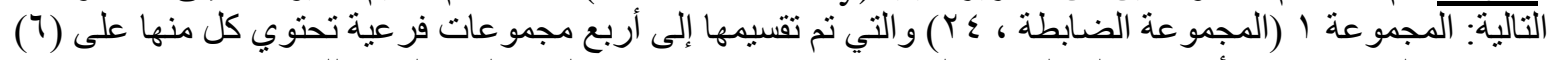

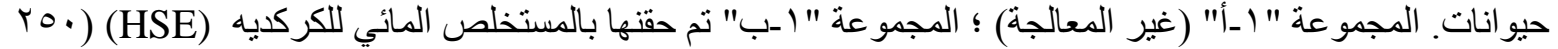

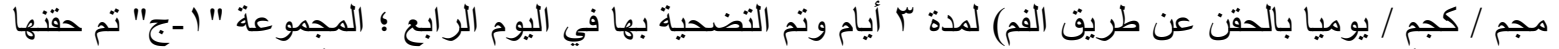

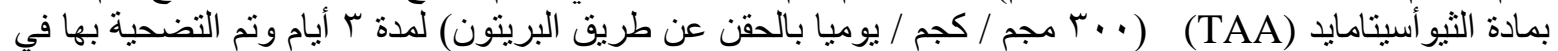

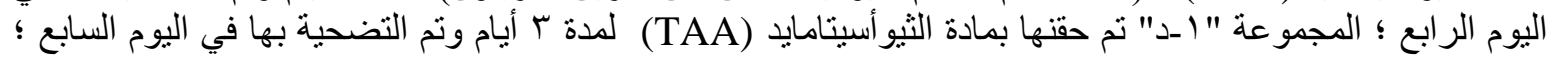

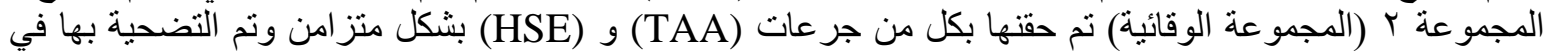

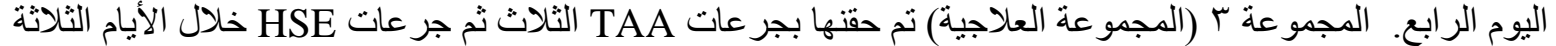
التالية وتم التضحية بها في اليوم السابع.

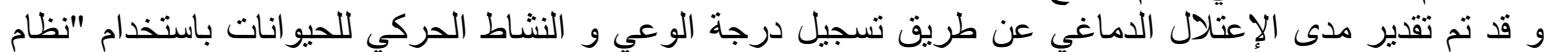

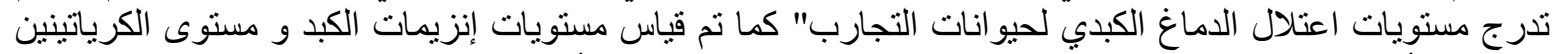

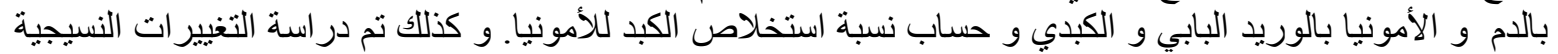

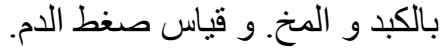

النتائج: تسببت مادة

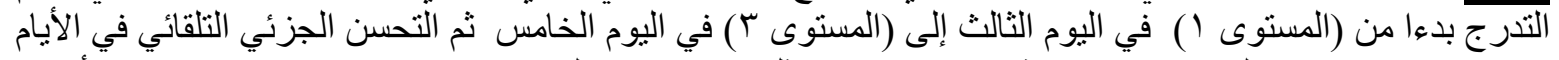

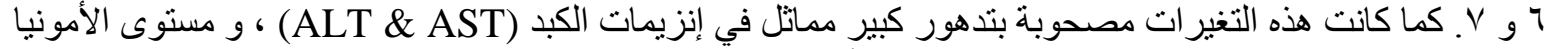
بالوريد البابي و الكبدي مع انخفاض نسبة استخر اج الأمونيا. و صاحب ذلكا للك تلف نسيجي في الكبد و الدماغ (وذمة الدماغ

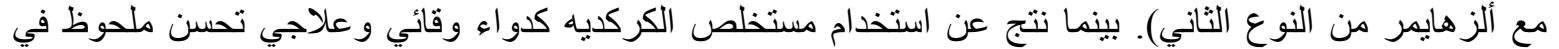

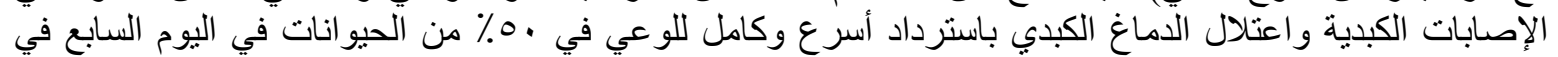

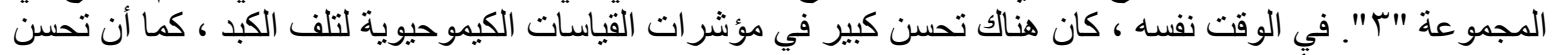

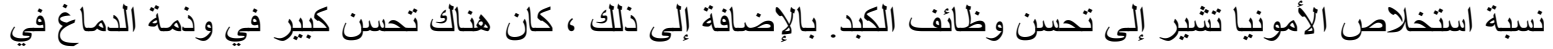

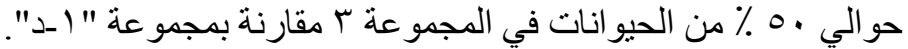

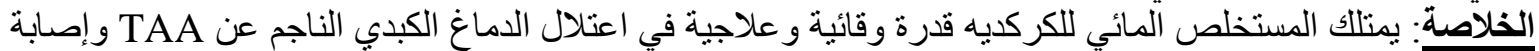

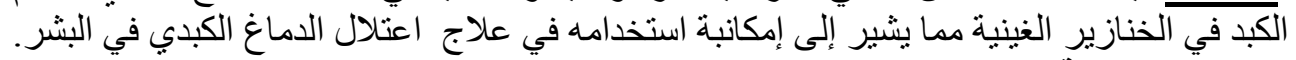

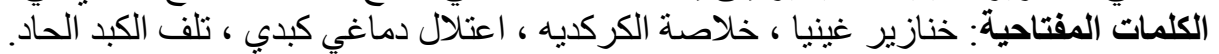

